\title{
Dilemas de uma Formação Médica: Relato de Experiência
}

Dilemmas of Medical Training: Experience Report

Dilemas de la Educacion Médica: Relato de Experiência

Cleide de Sousa Araújo ${ }^{1}$

\section{Resumo}

Objetiva-se relatar vivência acadêmica de estudante de Medicina de universidade pública localizada na região nordeste do Brasil. O novo sistema de seleção adotado para ingresso no ensino superior no Brasil, o Sistema de Seleção Unificada (SISU), possibilita ao aluno concorrer a vagas em qualquer estado do país. Por meio do SISU, tive a oportunidade de ingressar em um curso de Medicina em uma universidade pública e inserir-me no universo complexo da formação médica. Incorporar uma nova realidade, longe de familiares e dos amigos conquistados em toda uma vida, aprendendo a administrar com maturidade a rotina muitas vezes exaustiva exigida pelo curso, os desafios do aprendizado no cuidado do outro e aquele ainda maior, o desafio de cuidar de si, são apenas alguns dos dilemas enfrentados durante o percurso. A meio caminho do título de médica, ao passo em que me sinto convicta da escolha que fiz, vejo-me também cheia de incertezas quanto ao mercado de trabalho que me aguarda, ao papel que desempenharei na sociedade e trago ainda comigo muitas aspirações quanto ao meu grau de realização pessoal e profissional.

Descritores: Educação Médica; Educação Superior; Estudantes de Medicina.

${ }^{1}$ Graduanda em Medicina na Universidade Federal de Alagoas. Monitora da disciplina SS4. Campus A. C. Simões. Av. Lourival Melo Mota, s/n. Tabuleiro dos Martins. 57072-900. Maceió - Al, Brasil. Autora correspondente: cleiddearaujo@gmail.com

Recebido: 15/3/2016 - Aceito: 24/3/2016. 
Abstract

The objective is to report academic experience of public university medical student located in the northeast of Brazil. The new selection system adopted for entry into higher education in Brazil, the Unified Selection System (SISU), allows the student to apply for positions in any state in the country. Through SISU, I had the opportunity to join a medical school at a public university and put me in the complex world of medical training. Incorporating a new reality, far from family and friends won in a lifetime, learning to manage with maturity routine often exhaustive required for the course, the challenges of learning in the care of the other and that further, the challenge of caring for themselves are just some of the dilemmas faced along the way. Halfway through medical title of the way, while when I feel convinced of the choice I made, I am also full of uncertainty about the job market that awaits me, the role will carry in society and many aspirations about my degree personal and professional fulfillment.

Descriptors: Education, Medical; Education Higher; Students, Medical.

\section{Resumen}

El objetivo es dar a conocer la experiencia académica de una estudiante de medicina de universidad pública ubicada en el nordeste de Brasil. El nuevo sistema de selección adoptado para ingresar a la educación superior en Brasil, el Sistema de Selección Unificada (SISU), permite al estudiante aplicar a las vacantes en cualquier estado en el país. A través de SISU, he tenido la oportunidad de unirme a una escuela de medicina en una universidad pública y me puso en el complejo mundo de la formación médica. La incorporación de una nueva realidad, lejos de la familia y amigos ganados en la vida, aprender a manejar con madurez la rutina a menudo exhaustiva necesario para el curso, los desafios de aprendizaje en el cuidado del otro y que además, el desafío de cuidar de sí, son sólo algunos de los dilemas enfrentados a lo largo del camino. A medio camino del título de médica, mientras que me siento convencida de la elección que hice, yo estoy también llena de incertidumbre sobre el mercado de trabajo que me espera, el papel que voy a llevar en la sociedad y me llevo también, muchas 
aspiraciones de mi grado de realización personal y profesional.

Descriptores: Educación Médica; Educación Superior; Estudiantes de Medicina.

Introdução

A Medicina é uma prática milenar e universal em constante transformação. Especialmente nos dois últimos séculos, períodos de grandes descobertas no campo das ciências biológicas, bem como, desenvolvimento

$\mathrm{e}$
aperfeiçoamento de tecnologias que foram incorporadas à prática médica, tal saber tem se renovado e reinventado constantemente, principalmente no mundo ocidental.

Ingressar no curso de Medicina é aspiração de muitos jovens, seja por aptidão pessoal, influência familiar, perspectiva salarial no mercado de trabalho, encantamento com o corpo humano e seus mistérios, entre outros. Independente da motivação, o aspirante a médico é advertido que o caminho a ser trilhado desde o momento de sua escolha, ingresso na escola médica, anos de formação e atuação profissional lhe demandará tempo, disciplina e afinco.

\section{Método}

Trata-se de relato de vivência acadêmica, ocorrida entre outubro de 2013 e junho de 2016, por estudante do curso de Medicina de uma universidade pública localizada na região nordeste do Brasil.

\section{Resultados e Discussão}

O novo sistema de seleção adotado para ingresso no ensino superior no Brasil, o chamado Sistema de Seleção Unificada ou, simplesmente SISU, possibilita ao aluno concorrer a vagas em qualquer estado do país sem ter que sair de sua residência para realizar provas em cada instituição e, foi por meio do Sisu 2013, que ingressei na Medicina.

O sonho com a carreira médica trouxe-me para longe do seio familiar; tão perto de casa, na mesma região geográfica e, ao mesmo tempo tão distante, separada dos meus pelas cansativas 20 horas de uma viagem terrestre; pela incompreensível malha aérea e suas conexões no sudeste do país quando meu destino é dentro do próprio nordeste; pelo elevado custo das viagens; ou, simplesmente, pela rotina 
diária que às vezes impõe limites até mesmo para o tempo gasto em um simples telefonema.

A distância da família, dos amigos, a adaptação aos costumes, tradições, culinária, clima e peculiaridades locais, a adaptação à rotina de estudos, aulas, trabalhos e provas ou a administração financeira são alguns dos novos desafios enfrentados. Elencar o maior deles é tarefa que tento realizar até hoje.

Tão difícil quanto, é eleger o maior ganho que a Medicina me trouxe. Poderia falar do quanto aprendi a valorizar ainda mais a família e amigos distantes, e os cada vez mais raros momentos em que estamos juntos; ou da aquisição de novas habilidades como ouvir e compreender melhor o outro e suas necessidades; ou da maturidade e sensibilidade requerida para aprender a lidar com as diferenças; dos novos amigos que ajudam a tornar o percurso mais leve e até divertido; ou, das lições de administração financeira para aprender a ter dinheiro do primeiro ao último dia do mês, quando na verdade, não se tem muito dinheiro para administrar.

Na verdade, o conjunto dos ônus e bônus tem sua relevância e cada um tem sua parcela de contribuição para minha formação diária, seja pessoal ou academicamente.

O contato com o corpo humano, inicialmente através do cadáver que serviu de campo de estudo nas aulas de Anatomia ou, atualmente, de cada paciente com quem interajo nos cenários de prática a cada anamnese ou exame físico, são para mim uma espécie de ritual mágico onde me percebo diante de um universo que me é apresentado pouco a pouco à medida que avanço no curso. Quanto à mente humana, tenho convicção de que não serei capaz de conhecê-la em sua totalidade, ainda que dedique toda a minha vida ao seu estudo, fato que me deixa ainda mais instigada a estudá-la.

Deveras importante, tem sido também as experiências que me permitiram aproximar-me da comunidade e realidade que me cercam, conhecer as reais necessidades e anseios da população e, a partir disso, refletir e buscar viabilizar modos de atender tais demandas hoje e futuramente.

$\mathrm{O}$ que dizer da interação e integração com professores e colegas, da gratidão pela acolhida, preocupação e companhia diária, seja nos momentos de aprendizagem e estudo ou, simplesmente, quando nos permitimos 
sentar para conversar sobre algo que nos aflige ou dividirmos uma conquista. Sem dúvidas, os elos criados e relações estabelecidas tornam o tão temido percurso muito mais agradável.

Não poderia deixar de falar da luta que é tentar manter-se saudável, quando muitas vezes, entre uma aula e outra, não se encontra tempo suficiente para uma refeição adequada; quando diversas vezes, as horas de sono são escassas; quando se tem que enfrentar uma cobrança externa e principalmente de si mesmo para que se aprenda tudo rápido e perfeitamente; ou, quando se está privado do aconchego do lar e do convívio familiar tão importantes para a saúde emocional. Penso que é preciso tomar cuidado para não desaprender a cuidar de si, enquanto se aprende a cuidar do outro.

\section{Conclusão}

Hoje, a meio caminho do tão sonhado título de médica, ao mesmo tempo em que me sinto convicta da escolha que fiz, tenho inúmeras dúvidas acerca da realidade que encontrarei no mundo do trabalho. Anseio saber como de fato poderei contribuir para oferecer melhores condições de saúde aos que me rodeiam; e aspiro no futuro, ser uma profissional acima de tudo, feliz com minhas escolhas e realizada enquanto pessoa. 